\title{
Institutional Governance Practices in Jordan Government Units
}

Submitted 11/12/20, $1^{\text {st }}$ revision 23/01/21, $2^{\text {nd }}$ revision 14/02/21, accepted 20/03/21

\author{
Khleef A. Alkhawaldeh ${ }^{1}$
}

\begin{abstract}
:
Purpose: This research paper aims to examine institutional governance practices in Jordan government units.

Design/Methodology/Approach: Institutional governance practices incorporates the following aspects, legislation, structure and organization, policy and decision-making, human capital management, operations and procedures, financial management, resources management, performance management, and institutional culture. These institutional governance practices have been assessed by leaders responsible for institutional development in government institutions and companies listed in Government Units Budgets Law.

Findings: The findings indicate that the institutional governance practices and their related aspects exceed the average level. The research concludes that governance practices incorporate conforming to specifications and complying with frameworks, guidelines, and standards. They are improving the quality of delivering services and at the same time optimizing the use of resources, which enhances the trust in institutions and companies.

Practical Implications: Similar institutions and companies may use this assessment approach to assess governance practices and bridge the gaps or undertake further enhancements accordingly.

Originality/Value: To the best of the author's knowledge, previous studies have concentrated mainly on top management and board of directors' governance and focused on governance aspects. This study examines governance practices at the fundamental institutional level, incorporating the institution set-up, structure, frameworks, systems, processes, and machinery of an institution that ensures good governance efficiency, effectiveness, and overall performance.
\end{abstract}

Keywords: Governance, institutional governance, institutional governance practices, Jordan.

JEL codes: $H 1$.

Paper Type: Research study.

${ }^{1}$ Part-time Lecturer, Dept. of Business Administration, PSUT, khleef.k@gmail.com; 


\section{Introduction}

There are several definitions for governance, good governance, and corporate governance in literature. However, there is no common standard definition of governance. Based on the literature review and for this research, governance can be operationally defined as a set of frameworks and related practices that govern institutional work in terms of efficiency in managing resources and achieving goals. This may apply to all sectors regardless of the nature of roles, business, and functions.

Based on an extensive review of previous studies on governance, it is worth mentioning that some of the reviewed previous studies focused on few aspects of good governance in the private sector, such as banking, stock exchange, insurance, higher education, tourism fields (Mohamed, 2016; Padachi et al., 2016; Maheshwari and Meena, 2017; Abdeldayem and Aldulaimi, 2018; Asumadu, 2019). Some of them examined governance related to specific functions, such as financial, audit, procurement functions. Some of them concentrated mainly on top management and board of directors (Chen and Shapiro, 2011; Dipendra, 2016; Nourredine and Brahim, 2017; Arniati et al., 2019; Agnihotri and Gupta, 2019; Awadallah, 2020).

Therefore, a clear need for a study attempts to assess governance practices at the institutional level incorporating the set-up, frameworks, structure, systems, and machinery of an institution that ensure all enablers' good governance in terms of efficiency and effectiveness and the overall performance in general.

\section{Literature Review}

Aggarwal et al. (2007) found that $12.7 \%$ of foreign firms have a higher index than matching U.S. firms. Their findings indicated that minority shareholders of a typical foreign firm would benefit from an increase in governance investment. Chen and Shapiro (2011) argued that "good governance practices" in OECD countries (e.g., an active board of directors, separation of chairperson and the CEO, the significant presence of outside directors, and a two-tier board) could not reduce the negative impact of controlling-shareholder expropriation on corporate performance because the designed governance practices do not resolve any conflicts controlling and minority shareholders. Also, the board of directors is not independent of controlling shareholders.

Othman and Abdul Rahman (2014) highlighted the importance of ethical leadership attributes in directing governance practices. Mohamed (2016) found a significant difference between Islamic banks and conventional banks concerning corporate governance practices. Ali et al. (2016) identified the role of governance in having a collaborative knowledge management system. Isukul and Chizea (2016) indicated that democratic culture did not significantly enhance the institutional governance in many countries of the Economic Communities of West African States. 
Madhani (2016) mentioned that corporate governance is an institutional arrangement that provides the context for the decisions taken by top management and addresses the agency problem between shareholders and managers. Nadeem (2016) argued that the neo-liberal countries show a significantly distorted picture of good governance and decentralization. Dipendra (2016) referred that external governance in civil society organizations in Thailand identifies how to make the state mechanisms accountable, while internal governance concentrates more on the board's role in achieving the internal governance.

Padachi et al. (2016) found that the key factors that influence the corporate practices of companies listed on the Stock Exchange of Mauritius (SEM) incorporate the governance framework, reporting and conduct, and rewards. Kovač et al. (2016) proved that Slovene administration considers good Administration more as compliance to formal requirements than proactive support of a party and public benefit. Said et al. (2016) concluded that the Malaysian public sector should develop a sound governance system and a proper appraisal system to achieve an effective integrity system.

Thangaru and Kinyua (2017) examined the impact of organizational competence on corporate governance practices in the National Industrial Training Authority in Kenya and found that organizational competence positively influences corporate governance practices. Nourredine and Brahim (2017) found that the corporate governance in Algerian small and medium enterprises is intermediate, and the enterprises widely neglect the external and audit committee. Maheshwari and Meena (2017) concluded that the degree of Corporate Governance compliance is relatively good in SBI (Public Sector Bank).

Chimbari (2017) found that the principles-based soft law approach to corporate governance is incompatible with Zimbabwe's public sector landscape and suggested a rules-based legislative solution that will impose stringent regulatory oversight. Anttiroiko (2017) showed that Finland and New Zealand are evolutionary cases with low-profile anticorruption policies, whereas Singapore is an extreme case with an array of institutionalized anticorruption measures providing a fast track to good governance. Ofuani et al. (2018) indicated that Nigerian Public corporations comply with the stipulated codes mostly though not entirely, and in varying proportions by each corporation.

Aguilera et al. (2018) highlighted that applying a deviant governance practice is contingent on the governance regulatory environment and a company's governance capacity. Abdeldayem and Aldulaimi (2018) mentioned that Arab universities need to perceive the significance of clarifying the reason for governance. Endris and Nura (2018) investigated the impediments of good governance practice in Jimma town, particularly on Ginjo and Mandera Kochi Kebelle administrations, revealed that local government administration lacked the courage to enforce the law and policies to enhance good governance. 
Chigudu (2018) highlighted investors around the world place emphasis on good corporate governance. Good corporate governance must play a role in aligning the interests of politicians, bureaucrats, and the electorate. Kanchana and Samarakoon (2018) mentioned a corruption-free society in the development and good governance. They revealed that the adoption of e-governance enhances transparency and accountability of public sector activities and thereby efficiently delivering services to the public. Mishra and Mohanty (2018) highlighted that the association between corporate governance and companies' financial performance is debatable.

Arniati et al. (2019) indicated that the earnings quality-monitoring model is constructed from many variables' interaction. The governance mechanism incorporates ownership, commissioner board, audit committee and internal audit function, and internal control activity. Findings indicate commissioner board structure, internal audit function, and internal control activity have a significant effect on earnings quality partially. Paterson et al. (2019) focused on the critical analysis of policy and practice in the fight against corruption and the interactions between public sector companies, accounting, and the socio-economic and political environments.

AlHares et al. (2019) investigated compliance and disclosure of corporate governance mechanisms in the Middle East and North Africa countries. They found that the voluntary compliance and disclosure of governance mechanisms among MENA countries are low and vary substantially across countries. Jamaiudin (2019) revealed that implementing the National Transformation Policy in Malaysia is generally accepted despite variance in the policy outcomes, and it incorporates sound governance principles.

Asumadu (2019) indicated that good governance is imperative, and Gupta (2019) found that a smaller board size and a higher ratio of block ownership consistently seem to have better efficiency among the corporate governance factors. However, other corporate governance factors do not have a significant and consistent influence on efficiency. Ravšelj and Hodžić (2020) showed that public governance practices have important implications for business research and development activities.

Awadallah (2020) showed that board independence, CEO duality, and audit committees significantly associate with the audit process's quality, whereas institutional investors and managerial ownership have no significant influence on audit quality. Bincof (2020) examined the effects of recent reforms on Somalia's public sector and the impact on governance. This paper revisited a less focused on the question of public sector reforms. Beshi and Kaur (2020) examined the role of acceptable governance practices on public trust at the government's local level. They also found that transparency, accountability, and responsiveness had greater trust in the local Administration.

Mohammed and Hassan (2020) mentioned that the Codes of Good Governance Practice is a powerful tool to understand the latest developments in corporate governance practice and transparency and sound management principles. Meretu et 
al. (2020) assessed the practice and challenges of good governance at Hawassa city municipality and found that the administrative officials under Hawassa city municipality were less accountable and transparent in the process of service provision. They also found that Hawassa city municipality's governance practices faced obstacles, such as bureaucratic delay and incompetence, poor management, and corruption.

Previous studies mentioned above-examined governance practices in several sectors from different countries focusing on private sector companies. Many of these previous studies investigated the nature of associations between governance and other management concepts and practices, such as quality, transparency, accountability, and anti-corruption. The focus on the top management level was evident in the mentioned previous studies. Some of the highlighted key success factors are management independence from ownership, protection of the rights of minority shareholders, participative leadership, proper appraisal systems, and avoiding conflict of interests.

Based on that, assessing governance practices at the institutional level contributes to knowledge in this regard, and at the same time, similar institutions and companies to enhance institutional governance practices can use the implications of related aspects.

\section{Theoretical Framework and Methodology}

Based on literature review, this research attempts to assess institutional governance practices (Chen and Shapiro, 2011; Othman and Abdul Rahman, 2014; Ali et al., 2016; Madhani, 2016; Kovač et al., 2016; Said et al., 2016; Thangaru and Kinyua; 2017; Chimbari, 2017; Ofuani et al., 2018; Kanchana and Samarakoon, 2018; Jamaiudin, 2019; Bincof, 2020). As shown in Figure 1, institutional governance consists of the following aspects:

1. Legislation: This aspect includes its essential components and attributes, such as legislation focuses on core functions of the institution, comprehensiveness of legislation, clarity of legislation, the relevance of legislation, applicability and implementation of legislation and legislation ensures no overlapping or duplications in roles and functions with other institutions.

2. Structure and Organization: This aspect includes its essential components and attributes, such as the relevance of endorsed structure and organization in terms of size and structure, integrated functions, adequate supervision, and effective governed communication and reporting channels.

3. Policy \& Decision-Making: This aspect includes its essential components and attributes, such as implementation of approved manual or guidelines, factual and participative approach for policy \& decision-making, strategy alignment, strategy cascading, clear implementation responsibilities, specific timeframes, identified milestones, follow-up, and impact analysis and evaluation. 
4. Human Capital Management: This aspect includes its essential components and attributes, such as its functions, alignment of its plans, and related processes with strategy, empowerment, performance appraisal, merit basis, and codes of conduct.

5. Operations and Procedures: This aspect includes its essential components and attributes, such as simplified, accessible endorsed procedural manuals, communicated process and service standards, auditable automated and digitalized operations, and seamless integration and cooperation between and within institutions. Financial Management: this aspect includes its essential components and attributes, such as fiscal policy, budgeting, financial system and processes, expenditure review, reporting, and corrective actions.

6. Resources Management: This aspect includes its essential components and attributes, such as partnership, procurement system, processes, facilities and equipment management, preventive maintenance, utilization, storing management, technology management, and knowledge management.

7. Performance Management: This aspect includes its essential components and attributes, such as performance indicators, related international indicators, monitoring and evaluation system and process, internal control units, transparent reports and publications, and accountability.

8. Institutional Culture: This aspect includes its essential components and attributes, such as commitment, transparency of frameworks, systems and decisions, integrity and anticorruption, agility, excellence.

Institutional governance practices have been assessed from the perspectives of leaders responsible for institutional development in government institutions and companies listed Government Units Budgets law, the number of which is 57 government units.

The aspects of institutional governance practices mentioned above have been measured through a questionnaire consisting of questions for every aspect. The measurement scale consists of five points: 1 (poor), 2 (below average), 3 (average), 4 (above average) and 5 (excellent).

Figure 1. Research Model

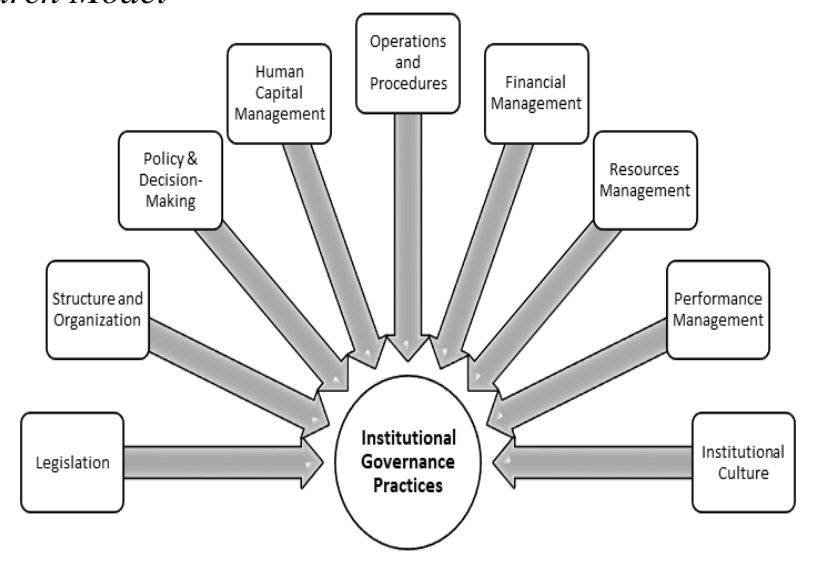

Source: Author. 
One main directional hypothesis and ninth minor directional hypotheses have been developed and then tested using appropriate statistical analysis techniques.

The main hypothesis:

H0: the level of institutional governance practices in Jordan government units is average.

H1: the level of institutional governance practices in Jordan government units is above average.

The first minor hypothesis:

H0: the level of governance practices in the legislation aspect is average.

H1: the level of governance practices in the legislation aspect is above average.

The second minor hypothesis:

H0: the level of governance practices in the structure and organization aspect is average.

H1: the level of governance practices in the structure and organization aspect is above average.

The third minor hypothesis:

H0: the level of governance practices in the policy and decision-making aspect is average.

H1: the level of governance practices in the policy and decision-making aspect is above average.

The fourth minor hypothesis:

H0: the level of governance practices in the human capital management aspect is average.

H1: the level of governance practices in the human capital management aspect is above average.

The fifth minor hypothesis:

H0: the level of governance practices in the operations and procedures aspect is average.

H1: the level of governance practices in the operations and procedures aspect is above average.

The sixth minor hypothesis:

H0: the level of governance practices in the financial management aspect is average. H1: the level of governance practices in the financial management aspect is above average.

The seventh minor hypothesis:

H0: the level of governance practices in the resources management aspect is average. 
H1: the level of governance practices in the resources management aspect is above average.

The eighth minor hypothesis:

H0: the level of governance practices in the performance management aspect is average.

H1: the level of governance practices in the performance management aspect is above average.

The ninth minor hypothesis:

H0: the level of governance practices in the institutional culture aspect is average.

H1: the level of governance practices in the institutional culture aspect is above average.

To ensure the validity of the measurement instrument, the draft questionnaire has been distributed to a number of experts and then has been developed based on the feedback, comments and suggestions received from them.

The final format of questionnaire has been distributed to leaders who are responsible for institutional development function in government institutions and companies listed in Government Units Budget Law.

Reliability tested for every single aspect of institutional governance using SPSS and the test outputs are shown in Table 1 below.

Table 1. Cronbach's Alpha

Source: Author.

\begin{tabular}{|l|c|}
\hline Aspect & Cronbach's Alpha \\
\hline Legislation & 0.932 \\
\hline Structure and Organization & 0.917 \\
\hline Policy and decision-making & 0.900 \\
\hline Human capital management & 0.899 \\
\hline Operations and procedures & 0.906 \\
\hline Financial management & 0.904 \\
\hline Resources management & 0.914 \\
\hline Performance management & 0.921 \\
\hline Institutional culture & 0.929 \\
\hline
\end{tabular}

As shown in Table 1 above, Cronbach's Alpha for the "human capital management" aspect equals 0.899, whereas it equals 0.900 and above for the other eight aspects of institutional governance. This means that the reliability of responses on the questionnaire is high. 


\section{Research Findings and Conclusion}

The descriptive statistics results for institutional governance practices and related aspects are shown in Table 2.

Table 2. Descriptive Statistics

\begin{tabular}{|l|c|c|c|c|c|}
\hline \multirow{2}{*}{\multicolumn{1}{|c|}{ Aspect }} & \multicolumn{5}{c|}{ Descriptive Statistics } \\
\cline { 2 - 6 } & $\mathrm{N}$ & Minimum & Maximum & Mean & Std. Deviation \\
\hline Legislation & 57 & 2.00 & 4.80 & 3.7895 & .71556 \\
\hline Structure \& Organization & 57 & 1.80 & 5.00 & 3.8000 & .80356 \\
\hline Policy \& Decision-Making & 57 & 1.60 & 5.00 & 3.8246 & .78383 \\
\hline Human Capital Management & 57 & 2.00 & 5.00 & 3.8316 & .69979 \\
\hline Operations \& Procedures & 57 & 1.60 & 5.00 & 3.8421 & .76227 \\
\hline Financial Management & 57 & 2.20 & 5.00 & 3.7825 & .77393 \\
\hline Resources Management & 57 & 1.80 & 5.00 & 3.7123 & .76066 \\
\hline Performance Management & 57 & 2.00 & 4.80 & 3.6667 & .79313 \\
\hline Institutional Culture & 57 & 1.60 & 4.60 & 3.3368 & .81955 \\
\hline Institutional Governance Practices & 57 & 1.98 & 4.80 & 3.7318 & .70991 \\
\hline Valid N (list wise) & 57 & & & & \\
\hline
\end{tabular}

Source: Author.

As shown in Table 2, the overall institutional governance practices' mean equals 3.7318 , which is closer to "above average $=4$ " than to "average $=3$ ". Except for the aspect of institutional culture, means of all other aspects of institutional governance are closer to "above average $=4 "$ than to "average $=3$ " as well. The mean of the institutional culture aspect equals 3.3368, which is closer to "average $=3$ " than to "above average $=4 "$. The standard deviation for institutional governance practices and all related aspects is less than 0.82 .

The results of the One-Sample T-Test are shown in Table 3. As shown in Table 3, sig. (2-tailed) for the overall institutional governance practices and the eight related aspects is .000 and for the institutional culture, aspect is .003. This indicates that all null hypotheses are rejected, and all alternate hypotheses are accepted. Therefore, the institutional governance practices and related aspects are above average.

Concerning the governance practices in the legislation aspect, the detailed findings indicate that the legislative frameworks focus on the institutions and companies' core functions. The legislative frameworks are comprehensive, relevant, applicable, and precise for implementation without any major overlapping or duplications with other institutions and companies. The legislative frameworks are aligned with the roles and functions undertaken by the concerned institutions and companies. The findings also indicate that the legislative frameworks are not periodically reviewed to revise them when needed. 
Table 3. One-Sample T-Test Results (Test Value = 3)

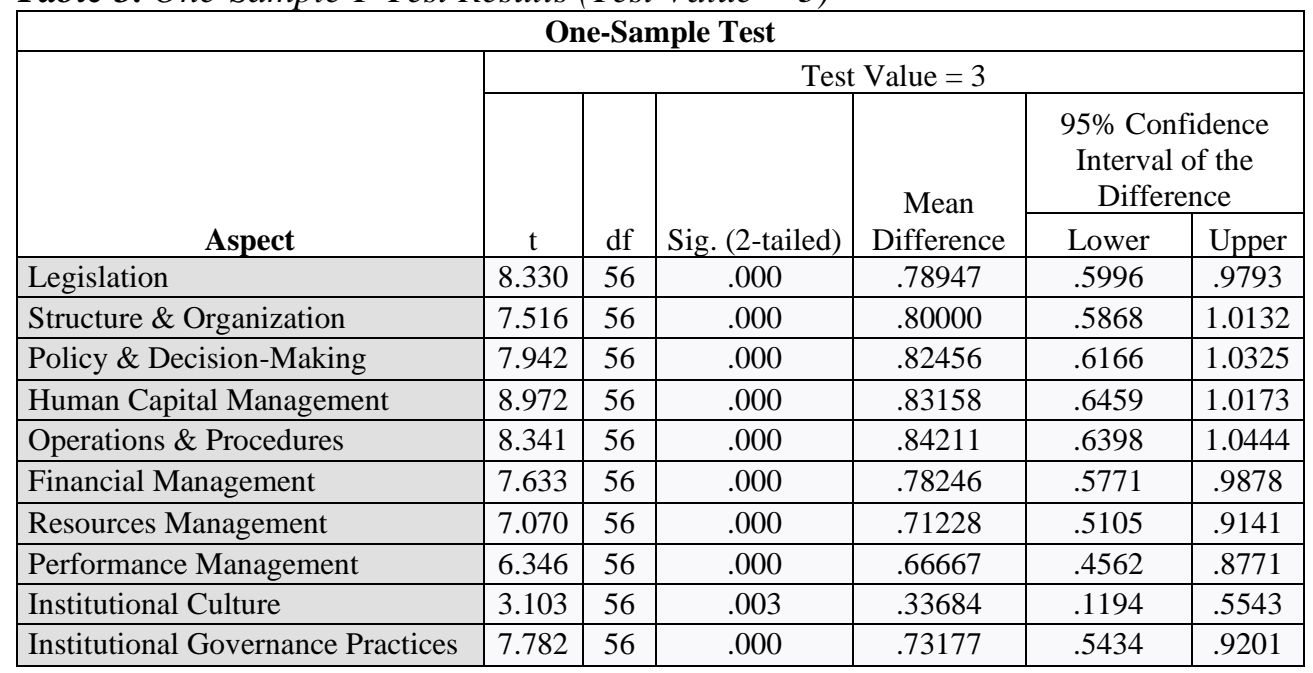

Source: Author.

Regarding governance practices in the structure \& organization aspect, the detailed findings indicate that institutions and companies' organizational structures reflect their core functions. Supervision, authorities' matrix, and communication channels are clear. However, the size and contents of organizational structures are unfit as more weight is given to support functions in terms of several people and budgets on account of core functions.

About the governance practices in the policy \& decision-making aspect, the detailed findings show that the institution's and companies' strategies are aligned with government policies and strategies. The participative approach is adopted to some extent in the development of critical strategies. Strategies are cascaded to lower levels in institutions and companies and translated to implementation plans with specific timeframes. There is a clear need to invest more effort in analyzing and evaluating the impact of policies and strategies as they cost money and consume time and pay more concern to scientific research to support the decision-making process.

Concerning the governance practices in the human capital management aspect, the detailed findings reveal that the functions of human capital management and related systems and manuals are implemented well in terms of recruitment, job description, performance appraisal, and empowerment. The alignment between human capital and corporate strategy is a vital matter that needs more concern in most institutions and companies.

Concerning the governance practices in the operations \& procedures aspect, detailed findings indicate transparent communicated processes and procedures. Some initial attempts for electronic and smart services and processes. The critical challenge is the legal requirements of such transformation to automation and digitalization. Ensuring the audit process's applicability in automation and digitalization initiatives is an issue 
to deal with and find a way to solve it. The cooperation and integration between and within institutions and companies are satisfactory.

Referring to the governance practices in the financial management aspect, the detailed findings support that robust financial systems and procedures. The budgeting mechanism and process are still traditional when there are some directives and initial attempts to move to a results-oriented budgeting system. Reviewing expenditures is crucial for the future of these institutions and companies.

Concerning the governance practices in the resources-management aspect, the detailed research findings highlighted that partnership initiatives are still at the beginning. The unified procurement system and processes are adopted in most government institutions with transparent procedures and decisions. Maintenance and storing systems ensure the existence of governance tools - more efforts are needed in knowledge management.

Regarding governance practices in the performance management aspect, the detailed findings indicate that this aspect's implementation level is lower than the above aspects. Institutions and companies are periodically issuing performance reports and internal control units in every institution and company. Some of these internal control units practice all control types (financial, administrative, technical), and others practice only financial control. The missing part is proper accountability and the immense necessity to follow up the related international indicators and take the required actions to improve the country's ranks and grades in these indicators and enhance its competitive advantage at the international level.

Concerning the governance practices in the institutional culture aspect, the detailed findings show that this aspect is the lowest implementation level comparing with other aspects. This finding is a logical point and makes sense as frameworks, systems, manuals; processes are designed, developed, and implemented first and in a much easier way than creating the culture, which takes time - implementing culture components and attributes such as commitment, transparency, integrity, and agility close to the average point.

The research concludes that governance practices incorporate conforming to specifications and complying with frameworks, guidelines, and standards. Thereby, they are improving the quality of delivering missions and services while optimizing the use of the available resources. This means spending public money to serve citizens in a responsible, wise way. All of these practices enhance people's trust in institutions and companies.

In general, the findings of this research are aligned with previous studies (Othman and Abdul Rahman, 2014; Kovač et al., 2016; Said et al., 2016; Thangaru and Kinyua, 2017; Chimbari, 2017; Anttiroiko; 2017; Ofuani et al., 2018; Kanchana and Samarakoon; 2018; Paterson et al., 2019; Bincof, 2020; Beshi and Kaur, 2020; Mohammed and Hassan, 2020). 
Institutions and companies can enhance their governance systems, values, and cultures at the institutional level through adhering to the principle of the rule of law, separating control and regulatory activities from execution, and enforcing accountability, improving monitoring and evaluation systems and related tools and processes. In addition to that, institutions and companies are recommended to apply risk management, resilience, and agility concepts. Moreover, they need to invest wisely in accreditation and quality and excellence systems and programs and anchoring the culture of integrity, equality, and transparency.

Finally, similar institutions and companies in other developing countries to assess governance practices and then bridging the gaps or undertaking further enhancements accordingly can use this assessment approach and utilize the implications of related aspects.

\section{References:}

Abdeldayem, M., Aldulaimi, S. 2018. Corporate Governance Practices in Higher Education Institutions: The UK vs Bahrain. International Journal of Learning and Development, 8, (4). Doi:10.5296/ijld.v8i4.13841 URL: https://doi.org/10.5296/ijld.v8i4.13841.

Aggarwal, R., Erel, I., Stulz, R., Williamson, R. 2007. Differences in Governance Practices between U.S. and Foreign Firms: Measurement, Causes, and Consequences. NBER Working Paper No. 13288, No. G30, G32, G34, G38, K22.

Agnihotri, A., Gupta, S. 2019. Relationship of Corporate Governance and Efficiency of Selected Public and Private Sector Banks in India. Business Ethics and Leadership, 3(1).

Aguilera, R., Judge, W., Terjesen, S. 2018. Corporate governance deviance. Academy of Management Review, 43(1), 87-109. Doi:10.5465/amr.2014.0394.

AlHares, A., Dominic, G., Al Abed, R. 2019. The Corporate Governance Practices: Evidence from MENA Countries. Theoretical Economics Letters, 9(4).

Ali, A., Nor, R., Abdullah, R., Murad, M. 2016. Developing Conceptual Governance Model for Collaborative Knowledge Management System in Public Sector Organizations. Journal of ICT, 15(2), 171-191.

Anttiroiko, A.V. 2017. Emulating Models of Good Governance: Learning from the developments of the world's least corrupt countries. International Journal of Public Policy, 13(1/2), 21-35.

Arniati, T., Puspita, D.A., Amin, A., Pirzada, K. 2019. The implementation of good corporate governance model and auditor independence in earnings' quality improvement. Entrepreneurship and Sustainability Issues, 7(1), 188-200. http://doi.org/10.9770/jesi.2019.7.1(15).

Asumadu, E. 2019. A Study on the Principles of Corporate Governance with Special to Reference to the Code of Best Practices Issued by SEC Ghana. International Journal of Research in Social Sciences, 9(8), ISSN: 2249-2496.

Awadallah, E. 2020. Measuring the effectiveness of selected corporate governance practices and their implications for audit quality: evidence from Qatar. Afro-Asian J. Finance and Accounting, 10(1), 24-47.

Beshi, T., Kaur, R. 2020. Public Trust in Local Government: Explaining the Role of Good Governance Practices. Public Organization Review, 20, 37-350. 
Bincof, M. 2020. The Effect of Public Sector Reform on Good Governance in Somalia. Public Policy and Administration Research, 10(9), ISSN 2224-5731.

Chen, V., Li, J., Shapiro, D. 2011. Are OECD-prescribed "good corporate governance practices" really good in an emerging economy? Asia Pac J Management, 28, 115-138. DOI 10.1007/s10490-010-9206-8.

Chigudu, D. 2018. Corporate governance in Africa's public sector for sustainable development: The task ahead. The Journal for Transdisciplinary Research in Southern Africa, 14(1),1817-4434. a512. https://doi.org/ 10.4102/td.v14i1.512.

Chimbari, P. 2017. Public Sector Corporate Governance in Zimbabwe: The Nexus between the Zimcode and State-Owned Enterprises. International Journal of Economics. Commerce and Management, 5(7). ISSN 23480386.

Dipendra, K. 2016. Determinants of internal organizational governance practices: Evidence from civil society organizations in Thailand. International NGO Journal, 11(1), 1-11. DOI:10.5897/INGOJ2016.0302.

Endris, F., Nura, K. 2018. Assessing the Impediments of Good Governance Practices in Local Government Administration; Case Study in Jimma Town, Ethiopia. International Journal of Multicultural and Multireligious Understanding (IJMMU), 5(4).

Isukul, A., Chizea, J. 2016. Institutional Governance Reforms: Examining the Case of ECOWAS. Asian Research Journal of Arts \& Social Sciences, 1(4), 1-12.

Jamaiudin, N. 2019. Good Governance in Malaysia: Assessing Public Perceptions on the Implementation of National Transformation Policy, 2011-2016. Intellectual DIscourse, 27, 719-743. ISSN 0128-4878 (Print); ISSN 2289-5639.

Kanchana, D., Samarakoon, A. 2018. The Role of E-governance in Curbing Public-Sector Corruption (A Theoretical Overview). OUSL Journal, 13(1), 5-27.

Kovač, P., Tomaževič, N., Leben, A., Aristovnik, A. 2016. Reforming public administration in Slovenia: between theory and practice of good governance and good administration, International Journal of Public Policy, 12(3/4/5/6), 130-148.

Madhani, P. 2016. The Relationship Between Ownership Types and Corporate Governance and Disclosure Practices of Firms Listed on Indian Stock Exchange. The IUP Journal of Corporate Governance, 15(1).

Maheshwari, M., Meena, S. 2017. Corporate Governance: An Empirical Study of State Bank of India. International Journal of Science Technology and Management, 6(1).

Meretu, T., Dagnew, B., Dana, D. 2020. Practices and Challenges of Good Governance in Ethiopia: The Case of Hawassa City Municipality, South Nation, Nationality and People Regional State, Ethiopia. International Journal of Development in Social Sciences and Humanities (IJDSSH), 3(1), 2455-7730.

Mishra, S., Mohanty, P. 2018. Does good governance lead to better financial performance? International Journal of Corporate Governance, 9(4), 462-480.

Mohamed, W. 2016. Corporate Governance Practices of the Middle East Banking Sector: A Comparative Analysis between Islamic and Conventional Banks. Journal of Finance and Bank Management, 4(1), 99-111, 2333-6072.

Mohammed, A., Hassan, E. 2020. Good Corporate Governance Practices: Towards Management by Results. Revue de Consolidation Compatible et de Management de la Performance, 5.

Nadeem, M. 2016. Analyzing Good Governance and Decentralization in Developing Countries. Journal of Political Sciences \& Public Affairs, 4, 209. Doi:10.4172/2332-0761.1000209. 
Nourredine, F., Brahim, Z. 2017. Corporate Governance Perspectives in Algerian Small and Medium Scale Enterprises. Global Journal of Management and Business

Research: Administration and Management, 17(2).

Ofuani, A., Sulaimon, A., Adebisi, S. 2018. Corporate Governance Practices: A Comparative Study of Selected Public Corporations in Nigeria. Academic Journal of Economic Studies, 4(1), 192-202, 2457-5836.

Othman, Z., Abdul Rahman, R. 2014. Attributes of Ethical Leadership in Leading Governance. International Journal of Business and Society, 15(2), 359-372.

Padachi, K., Urdhin, H., Ramen, M. 2016. Assessing Corporate Governance Practices of Mauritian Companies. International Journal of Accounting and Financial Reporting, 6(1), 2162-3082.

Paterson, A., Changwony, F., Miller, P. 2019. Accounting control, governance and anticorruption initiatives in public sector organizations. The British Accounting Review. 51(5).

Ravšelj, D., Hodžić, S. 2020. The Role of Public Governance Practices for Business R\&D Activity in the EU. Central European Public Administration Review, 18(1), 125141.

Said, J., Alam, M., Khalid, M. 2016. Relationship between Good Governance and Integrity System: Empirical Study on the Public Sector of Malaysia. Humanomics. 32(2), 151-171.

Thangaru, M., Kinyua, G. 2017. Influence of Organizational Competence on Corporate Governance Practices in National Industrial Training Authority. International Journal of Education and Research, 5(3). 